\title{
Debates in the Metaphysics of Time
}

L. NATHAN OAKLANDER (ED.)

London: Bloomsbury, 2014

xiv +293 pp.

ISBN 9781780934907 (paperback)

This book is unusual in its breadth. It's a collection of original essays by metaphysicians, philosophers of mind, and philosophers of religion, loosely grouped into three parts: 'Metaphysics and time', 'Consciousness and time', and 'God, time, and human freedom'.

It begins with a section on Yuval Dolev's book 'Time and Realism: Metaphysical and Anti-metaphysical perspectives' (MIT press, 2007), in which he claims that a central debate in the metaphysics of time is based on a confusion. He targets what he calls the dispute between 'tensed' and 'tenseless' theories, which he also thinks of as a dispute between A- and B-theorists, and between presentists and eternalists.

The first contrast ('tensed' versus 'tenseless' theories) may refer to a disagreement over whether there are tensed facts, and/or to a disagreement over whether there are temporal propositions whose truth-value changes, and to which these tensed facts correspond. The second contrast ('A- versus Btheories') concerns whether A-properties such as pastness, presentness, and futurity are genuine monadic properties of events (or objects). The third contrast ('presentism' versus 'eternalism') is about whether, as presentists think, the present is all that exists.

One mistake Nathan Oaklander repeatedly attributes to Dolev is to overlook the version of the tenseless view that Oaklander favours, which includes the claim that temporal relations like 'earlier than' are dynamic, and experienced as such. So it seems as though he takes much of Dolev's critique to be effective against a more standard tenseless-tensed contrast. However, it seems to me that most of his objections to Dolev's arguments don't depend on his view. For example, his rejection of Dolev's claim that both sides agree there are 'tenseless relations' (though not on whether there are also 'tensed relations') just turns on the observation that if 'tenseless relations' are temporal relations that hold between terms that don't have A-properties, A-theorists don't posit them.

In his response, Dolev begins by noting that Oaklander seems to agree with his critique as applied to a more standard dispute, and then objects to the notion of a specious present, and various models thereof. He does this because he takes this to be an essential and characteristic ingredient in Oaklander's view of the phenomenology. But, we are told, calling the present 'specious' is 'in the same sprit' as calling it 'illusory'.

Francesco Orilia then argues against Dolev's contention to have shown the way to a 'post-ontological' or 'phenomenological' stage of theorizing about time. One 
of his main claims is that Dolev is in fact committed to eternalism, which is of course an ontological position.

The second section consists of three papers that don't directly address one another. Erwin Tegtmeier's contribution contains extended reflections on the views and arguments of historical figures, including Aristotle and McTaggart. Like Oaklander, Tegtmeier favours a Russellian relationist view, on which there are no times but only temporal relations, and these relations are dynamic rather than static.

Oreste Fiocco's aim is to propose a new metaphysics of time that is superior to both eternalist ('ontologically homogenous') and non-eternalist ('ontologically heterogeneous') accounts. He distinguishes between 'absolute becoming', the coming into being and ceasing to be of moments, and 'atemporal becoming', the coming to be of atemporal entities (such as 'simple facts') outside of time. Fiocco recognizes that the notion of atemporal becoming is difficult. But he suggests that it is needed to make progress. Existing theories fail to acknowledge that 'there is more to the world than the world in time', and overlook the 'initially perplexing phenomenon of atemporal becoming'.

The resulting view, though, seems close to existing non-eternalist views that posit 'simple facts' (which seem to be tenseless facts) such as 'Aristotle is a philosopher (at m)'. Such views raise intelligibility concerns of their own, but it's not clear that they need a notion of atemporal becoming.

The last paper of the first part is Joshua Mozersky's defense of a tenseless, Btheoretic account of temporal passage. It thus zooms in on a theme that is echoed in several previous contributions, such as Oaklander's and Tegtmeier's (and also helpfully articulates how Mozersky's thesis is more general: it's compatible with, but doesn't require relationism, or any particular ontological stance on Brelations). Mozersky argues that just as a relational view of ordinary predicates (which takes them to be relations to times) is the best solution to the puzzle of change, so a relational (and hence B-theoretic) view of A-predicates is the best view of temporal passage.

The second part of the book reflects on the nature of temporal experiences, which present the experiencing subject with such things as duration, order and change. Its main focus is the disagreement between extensionalists and atomists, who agree that there are such experiences. Their disagreement concerns whether temporal experiences are themselves temporally extended and mirror the temporal structure of the experienced events (extensionalism), or whether they are temporally unstructured (atomism).

Michael Pelczar argues against Barry Dainton's extensionalist view. For Dainton, a stream of consciousness consists of a succession of temporally extended specious presents that overlap by sharing parts. Pelczar assumes that some form of dualism is correct, and suggests that this means that the 'law of experience', which ensures that our experiences are collectively interpretable as being of a law-governed world, is fundamental. He then argues that if experiences occur in 
physical time, each temporally basic experience is confined to a single space-time point ('Russell's thesis'), and that since this is so, Dainton's view entails a violation of time-reversal invariance. In a time-reversed counterpart of our world, a Dainton-style series of experiences of movement from A to B, B to C, C to $\mathrm{D}$ would become the un-interpretable $\mathrm{C}$ to $\mathrm{D}, \mathrm{B}$ to $\mathrm{C}$, and $\mathrm{A}$ to $\mathrm{B}$.

Geoffrey Lee then briefly argues for atomism, and proceeds to defend it from objections. The way he sees it, atomism alone is in line with the empirical evidence about the timing of the neural events that underpin experience. Moreover, commonly heard philosophical objections miss their mark. For example, since atomism says that at a single time, one perceives events as happening at different times, the simultaneity objection (that on atomism, temporally separated events would be perceived as simultaneous) is a mistake.

Dainton responds to Lee by pressing just such objections, such as the multiple presentation worry. Since on atomism, the content of experiences is temporally extended, the same event can appear in the content of a series of consecutive experiences. The objection is that it should then be heard over and over. While Lee thinks the atomist is only committed to our experiencing the event for a while, Dainton takes his reply to require some unknown mechanism by which the brain systematically represses experiential contents.

In response to Pelczar, Dainton makes a number of points, the last one relating to violations of time-reversal invariance. However, some of his earlier points already throw into doubt Pelczar's reasons for holding 'Russell's thesis', a key premise in the argument. They also bring out that it's not clear that if there is a problem, it arises for extensionalists in particular.

The third part of the book consists of two pairs of papers on topics in the philosophy of religion in which time plays a central role. Joseph Diekemper defends divine temporality (the thesis that God is temporal) by arguing that events are necessarily temporal, and that God is necessarily the subject of events, both prior and subsequent to creation. In order to support the first claim, he feels the need to argue that events are necessarily temporally extended. Considerations in favour of the second claim include the biblical depiction of God as seemingly experiencing successive mental events, and the idea of God's joyful anticipation of creation (which he presents as a version of the idea that God has always been creating).

Brian Leftow counters Diekemper's arguments for both of these claims. He also points out that the second claim begs the question against the divine atemporalist, by assuming that there necessarily is time before creation. The atemporalist thinks that time is created, so since there is no time before time, there is no time before creation.

The second pair of papers is about the dilemma that divine foreknowledge seems to pose for human freedom. Specifically, they focus on the merits of the 'Anselmian' solution proposed by Katherin Rogers, which includes eternalism, divine atemporality, and the idea that God's timeless knowledge is explained by 
our free actions. Alan Rhoda contends that far from solving it, both eternalism and divine timelessness exacerbate the problem. It's clear from the exchange that much depends on prior questions surrounding time and freedom, such as whether freedom requires alternate possibilities and/or non-eternalism.

The book certainly provides food for thought for those already engaged in any of these debates. By presenting snapshots of disputes in areas that are not often considered together, it can perhaps stimulate reflection on their inter-relations, and so on the nature of the metaphysics of time.

NATALJA DENG

Faculty of Philosophy \& Faculty of Divinity

University of Cambridge

Sidgwick Avenue

Cambridge, CB3 9DA

Email: nmdeng@gmail.com 